\title{
EPIDERMOLYSIS BULLOSA \\ A REVIEW OF ANAESTHETIC PROBLEMS AND CASE REPORTS
}

\author{
A.R. Ramachandra Reddy, B.SC., M.B., B.S., C.R.C.P.(C), \\ and DAVID H.W. WoNG, M.B., B.s.
}

EPIDERMOLYSIS BULLOSA is a rare hereditary mechano-bullous skin disorder, which is a chronic and primarily non-inflammatory condition presenting with erosions or blisters usually resulting from relatively minor skin trauma. It has a worldwide distribution, but reliable data on the incidence among different racial groups are not available.

Von Hebra ${ }^{1}$ gave the first description of the simplex type, and Fox ${ }^{2}$ the first detailed description of the dystrophic type. Goldscheider ${ }^{2}$ should also be given credit for his first careful description of the simplex variety. The term epidermolysis bullosa was introduced by Koebner ${ }^{4}$ for his four cases occurning in the same family.

The various aspects of the disease have been studied and well documented in the dermatology literature. The condition has also been reported in the anaesthetic literature. ${ }^{5-8}$

\section{Cinasstatcatton}

There are two groups of mechano-bullous diseases: the non-scarring and the scarring. ${ }^{10}$ Epidermolysis bullosa simplex belongs to the non-scarring group. The other members of the group include junctional bullous epidermatosis, bullous congenital ichthyosiform erythroderma, acrodermatitis enteropathica, benign familial pemphigus and pachyonychia congenita. All these conditions have a dominant inheritance except junctional bullous epidermatosis which is recessive.

Epidermolysis bullosa dystrophica with its three types (dominant, recessive and "acquired") belongs to the scarring group. Also included in this group are Mendes Da Costa Syndrome (sex-link recessive), cutaneous porphyria (dominant or recessive) and localized collagen dystrophy (inheritance not determined).

This paper will deal only with the simplex and dystrophic types of epidermolysis bullosa.

\section{Ceinical Manifestation}

The basic presentation is the formation of bullae due to separation within the epidermis and their filling within a short time with fluid following minor trauma. The most appropriate stimulus is a frictional trauma with a lateral shearing force applied to the skin (Kikolsky sign). The entire skin and to varying degrees the mucous membranes are susceptible. Bleeding into the bullae may or may not

Department of Anaesthesiology, Children's Hospital, Vancouver, British Columbia.

$$
536
$$

Canad. Anaesth. Soc. J., vol. I9, no. 5, September 1972 


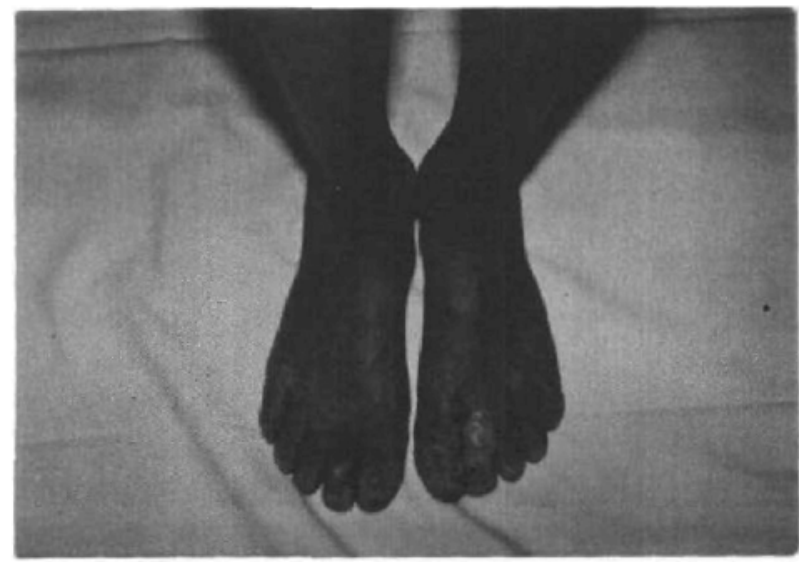

Figure 1

occur. The condition is worse in warm weather. ${ }^{11}$ Secondary infection is common. The usual offending organisms are haemolytic staphylococcus aureus and $\beta$-haemolytic streptococci. From this basic feature are derived the different variants of the disease.

\section{Epidermolysis bullosa simplex}

The bullae are usually present at or shortly after birth, and are inherited as a Mendelian dominant. The hands, finger tips and knuckles are characteristic sites; other common sites are the knees, feet, elbows and shoulders, although any area of skin may be involved. Healing is usually rapid. The areas involved may become hyperpigmented or depigmented, usually without scarring. Nails are sometimes affected (Figure 1). The condition remains active throughout life. Some patients improve markedly at puberty. There is no direct effect on the general health. Associated illnesses are coincidental, and the life span is normal.

Some patients in this group remain in the subclinical state until they are exposed to an unusual degree of trauma, and very often remain unrecognized. A number of cases were diagnosed among U.S. soldiers during the Second War, presenting with bullae formation on the feet following a long march. ${ }^{12}$

\section{Epidermolysis bullosa dystrophica}

Dominant form. During early infancy the lesions are similar to the simplex type. The bullae are mostly on the hands and feet. They heal with superficial soft scars and a wrinkled surface. Hyperpigmentation and depigmentation may occur. Mild oral mucous membrane lesions are common. Dental lesions may occur. Nails are dystrophic. Deformity is uncommon.

Recessive form. A history of consanguinity is frequent. The lesions may be present at birth, mostly on the feet. Scarring may lead to deformity, contracture and fuston of digits. Basal and squamous cell carcinoma may develop in the scars. ${ }^{13}$ Opening of the mouth may be restricted by intra-oral scarring. Erosions and ulcerations are common in the mucous membranes. Occasionally leukoplakia and 
even carcinoma may ensue. The tongue may be adherent to the base of the al veolar ridge. ${ }^{0}$ The teeth are dystrophic and susceptible to caries. Oesophageal stricture leading to dysphagia is not uncommon. ${ }^{14}$ The conjunctivae and corneae may show erosions and scarning; scleromalacia perforans may occur. ${ }^{15}$ Occasionally skin or visceral amyloidosis develops.

In severe cases, retardation of growth and development results. Iron deficiency anaemia, skeletal demineralization, ${ }^{14}$ shortened clotting time ${ }^{16}$ and serum protein abnormalities related to chronic infection and debilitation are associated findings. However, no consistent coagulation abnormalities could be found by some workers. ${ }^{17}$ The prognosis is guarded. Many patients die in infancy or childhood, but some survive to adulthood. Death may result from loss of great sheets of epidermis in infancy, but more commonly is due to infection, while occasionally it is caused by amyloidosis and renal failure.

"Acquired" form. There is no evidence of hereditary transmission. The lesions usually appear after infancy, most commonly on the hands, elbows and knees. The skin fragility may be sharply localized or wide-spread. The lesions may heal with superficial scars. The nails may or may not be involved.

\section{Patholocy}

In the simplex type, the vesicles and bullae occur within the epidermis. The cleavage elevates the stratum corneum from the stratum granulosum, but occasionally occurs deeper in the Malpighian layer. The elastic tissue is not destroyed and no scarring occurs on healing. In the fresh specimen, electron microscopy reveals cytolysis starting around the nucleus and spreading rapidly to the periphery.

The basic pathological change is the same in the dominant, recessive and "acquired" types of epidermolysis bullosa dystrophica. The separation here is between the dermis and epidermis. Elastic tissue is destroyed and scar is formed. Electron microscopy shows the separation to be just beneath the basement membrane with degeneration of connective tissue and absence of anchoring fibers.

\section{AETTOLOCY}

The pathogenesis of epidermolysis bullosa is uncertain. Over the years a number of theories have been proposed, namely: weakness of epidermal continuity; $;^{3,4}$ deficiency of elastic tissue;: ${ }^{18.13}$ malformation of cutaneous blood vessels allowing transudation of serum into the epidermis, in turn causing bullae formation; ${ }^{20,21,27}$ endocrine dysfunction including the thyroid, adrenals and gonads; ${ }^{22,23}$ and allergic mechanisms. ${ }^{24}$ However, most of these theories are purely speculative. For instance, total absence of elastic tissue in the dermis does not result in blister formation, nor can the endocrine theories be the answer.

Recent histochemical and electron microscopical studies do throw some light on the pathophysiology of the disease. It has been proposed that in the simplex variety, mechanical trauma activates cytolytic enzymes within the cells of the epidermis, leading to cell destruction and eventual formation of bullae. In the 
dystrophic variety, structural abnormality of the sub-basement membrane connective tissue may be the basic defect, ${ }_{3}^{10}$ affecting most likely the collagen, or being due to enzymatic attack at this location.

\section{Differential. Diagnosis}

The diagnosis is mainly based on the history and on the finding of bullae. A positive Kikolsky sign (separation of epidermis and dermis with friction) is strongly suggestive of the disorder, particularly the recessive dystrophic type. There is no consistent abnormality in laboratory tests. During infancy and childhood, one has to differentiate epidermolysis bullosa from bullous impetigo, con. genital syphilis and juvenile dermatitis herpetiformis. In adults, pemphigus, dermatitis herpetiformis, erythema multiforme, cutaneous porphyria and drug eruption may resemble the condition.

\section{TREATMENT}

The essence of management is avoidance of trauma to the skin. Rough and stiff clothing must be avoided, and well-fitting soft shoes should be wom. Sharp corners of furniture have to be removed. Air conditioning is recommended to avoid excessive heat. For the blisters and bullae themselves, cold compress and protective dressings are useful. Corticosteroids may be used topically, but their systemic use is hardly justified except on rare occasions. Antibiotics are used for treating secondary infections. Many patients require iron therapy for anaemia. Mucous membrane ulcerations, restriction from scarring and in some patients oesophageal stricture may lead to malnutrition and underdevelopment. Careful selection of food is important.

As the patients grow older, they learn to protect themselves from unnecessary trauma. One important aspect of the disease is that patients are often very selfconscious about their condition, and great tact and understanding must be exercised in managing them.

\section{Case Reports}

Case 1. The first patient, G.S., was admitted to the Day Care Unit of our hospital $11 / 2$ hours before dental work under general anaesthesia on March 15, 1972, accompanied by a note saying he had "ectodermal dysplasia." He was a shy 12 -year-old boy, weighing $27.7 \mathrm{Kg}$. There were areas of hyperpigmentation and depigmentation all over the body. Isolated, collapsed bullae were found on the fingers, hands, knees and feet. The nails were hypoplastic and some were absent. There was no scarring, and no sensory impairment. No other gross abnormality was detected.

He had been diagnosed as having epidermolysis bullosa soon after birth. He had widespread bullae, and these were periodically infected by haemolytic staphylococci and streptococci. There was no scarring of the lesions. It was noted that the lesions were not as bad and the nails were improving as he grew 
older. He received intermittent antibiotics for the secondary skin infections, and iron therapy for hypochromic, microcytic anaemia. Tests for porphyria were negative. He had phenobarbital for sedation while in hospital. He had developed acute glomerulonephritis in 1968. Follow-up studies showed normal kidney function by 1970 .

He was premedicated with chloral hydrate $1100 \mathrm{mg}$ and hyosine $0.22 \mathrm{mg}$ orally after examination. On arrival in the operating room, an intravenous drip of 3.3 per cent dextrose and 0.3 per cent saline was put in the left foot and taped. Anaesthesia was induced with a halothane-nitrous oxide-oxygen mixture. Three-quarters of a millilitre of 4 per cent Lidocaine was applied to the vocal cords and trachea through an Intracath attached to a syringe. A minute later, a $28 \mathrm{Fr}$ Portex nasotracheal tube was inserted through the right nostril, and a pharyngeal pack was put in place under direct vision. Anaesthesia was maintained with halothane ( 0.7 per cent), nitrous oxide $(3 \mathrm{l} / \mathrm{min})$ and oxygen $(2 \mathrm{l} / \mathrm{min})$. Breathing was spontaneous through a non-rebreathing circuit. The patient was monitored with a respiration meter, a pulse meter and a precordial stethoscope. The dental restoration took $2 \frac{1 \%}{2}$ hours, and the course of anaesthesia was uneventful. A few blisters were noted on the inmer aspect of the lips. When the tapes used for securing the endotracheal tube, the intravenous needle, and the precordial stethoscope were removed, the skin came right off, leaving large raw areas with serous discharge (Figures 2 and 3 ). The raw areas were immediately protected with Telfa dressing. There was no stridor on removal of the endotracheal tube. By the next morning the patient was up and about and did not seem to worry about the damage done to him.

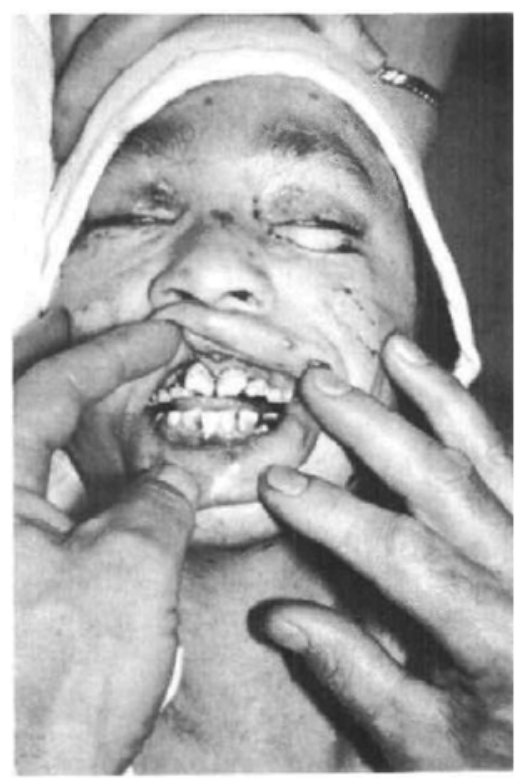

Figure 2 


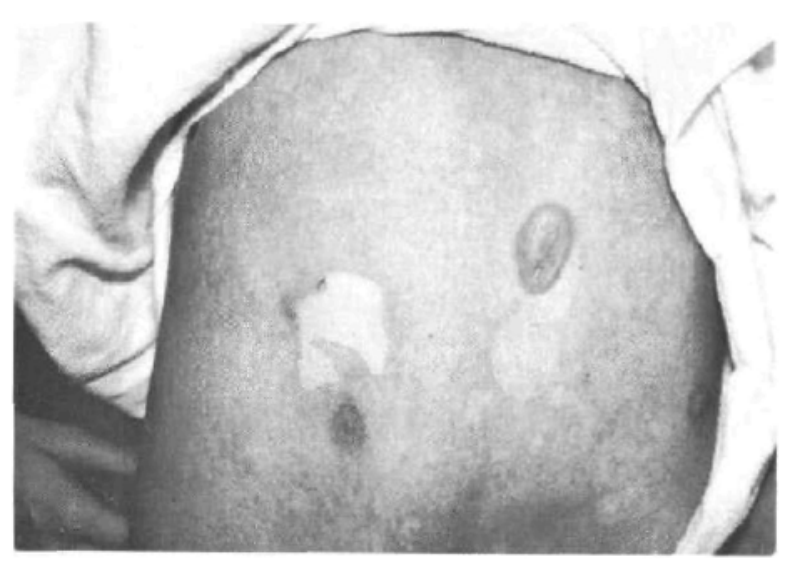

Figure 3

At this time it was learned that his brother would be coming in for the same procedure the following week. This prompted us to investigate their medical history in detail, so that the same happening could be avoided.

Case 2. M.S., our second patient, was two years older than his brother, the first patient. He had suffered from blisters of the skin since birth, and was also periodically infected by haemolytic staphylococci and streptococci. Even light clothing irritated the lesions, and sunlight was said to make them worse. The nails were dystrophic, and the oral mucous membrane was mildly affected from time to time. There was no scarring. Like his brother, the condition had improved over the years.

He had had periodic staphylococcal urinary infection. Hypochromic microcytic anaemia with haemoglobin as low as $8 \mathrm{gm}$ per cent was present and he was on iron therapy. Tests for porphyria were negative. He too had phenobarbital for sedation while in hospital. In 1969, he had developed Henoch-Schoenlein purpura and proliferative glomerulonephritis, proven by biopsy. He had hypertension, and continued to have haematuria and severe proteinuria. Methyldopa, azothioprine and prednisone had been started in April 1969; in January 1970, methyldopa was stopped, and by the following month, both azothioprine (Imu$\left.\operatorname{ran}^{9}\right)$ and prednisone were discontinued.

He was admitted to hospital on March 22, 1972, the day before scheduled dental work. He was fourteen years old and weighed $34.6 \mathrm{Kg}$. Areas of hyperpigmentation and depigmentation were noted. New lesions were not as numerous as in the case of his brother. No abnormality was detected in the heart and lungs. Haemoglobin was $11.2 \mathrm{gm} \%, \mathrm{BUN} 12 \mathrm{mg} \%$ and senum electrolytes were normal. Urinalysis showed presence of $10 \mathrm{mg}$ protein.

Premedication consisted of diazepam (Valium $5 \mathrm{mg}$ and hyosine $0.35 \mathrm{mg}$ given intramuscularly one hour preoperatively. No steroid coverage was thought to be necessary. On arrival at the dental office, an intravenous drip of 3.3 per cent dextrose and 0.3 per cent saline was started with a 21 -gauge Butterfly needle (Abbott) in the left foot. To avoid tapes, a soft-roll of the kind generally 


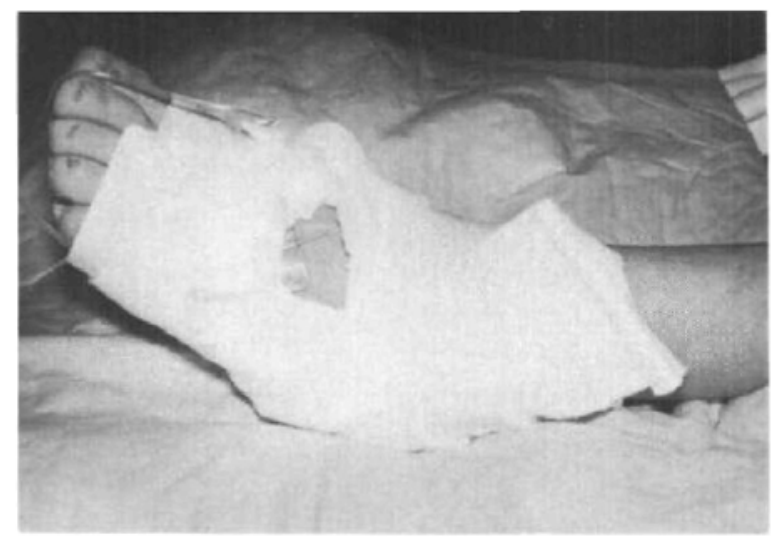

Figure 4

used for under-padding for plaster casts was used to wrap around the foot to secure the needle (Figure 4).

Pre-oxygenation with a high flow of oxygen was achieved with a mask held just over the face without actually touching it. Anaesthesia was induced with atropine $0.3 \mathrm{mg}$, thiopentone $250 \mathrm{mg}$ and succinylcholine $40 \mathrm{mg}$ intravenously and $3 \mathrm{ml}$ of 4 per cent lidocaine was applied to the cords and trachea. A $28 \mathrm{Fr}$ oral endotracheal tube was gently inserted. Anaesthesia was maintained with halothane $(0.75-1.0$ per cent $), \mathrm{N}_{2} \mathrm{O}(2 \mathrm{l} / \mathrm{min})$ and $\mathrm{O}_{2}(2 \mathrm{l} / \mathrm{min})$ administered through a non-rebreathing circuit. Respiration was spontaneous. Monitoring consisted of use of a respiration meter and palpation of the superficial temporal arterial pulse. No tape was used to secure the endotracheal tube. The corrugated tubing was suspended over the head by taping onto supports, thus assuring that no part would be in contact with the face (Figure 5). The face itself was covered with several layers of saline-soaked gauze. The pharyngeal packing, also saline soaked, was gently put into place under direct vision, to serve as a seal compensating for the smaller tube used, and also as an added fixation for the tube. The mouth gag was applied to the molars, one side at a time, care being taken to avoid any part of the handles touching the face. $A$ rubber dam was not used for the dental procedure so that all parts of the oral cavity could be seen and trauma avoided. Retraction of the lips was applied gently through moistened cottonoids. The procedure took four hours. Only one small blister was observed at the angle of the mouth and the upper lip was minimally swollen. The patient was transferred from the dental table to the stretcher by lifting the bed sheet and avoiding any movement between the skin and the sheet. Taking all these precautions, we were able to avoid bullae formation on any part of the skin.

There was no stridor on extubation. By the next morning the swollen lip had returned to normal and the bulla in the cheek had subsided (Figure 6). No bullae or erosions were observed around the intravenous site. He was discharged in the afternoon on the day following operation.

These patients came from Indian parents living in the northem part of British 


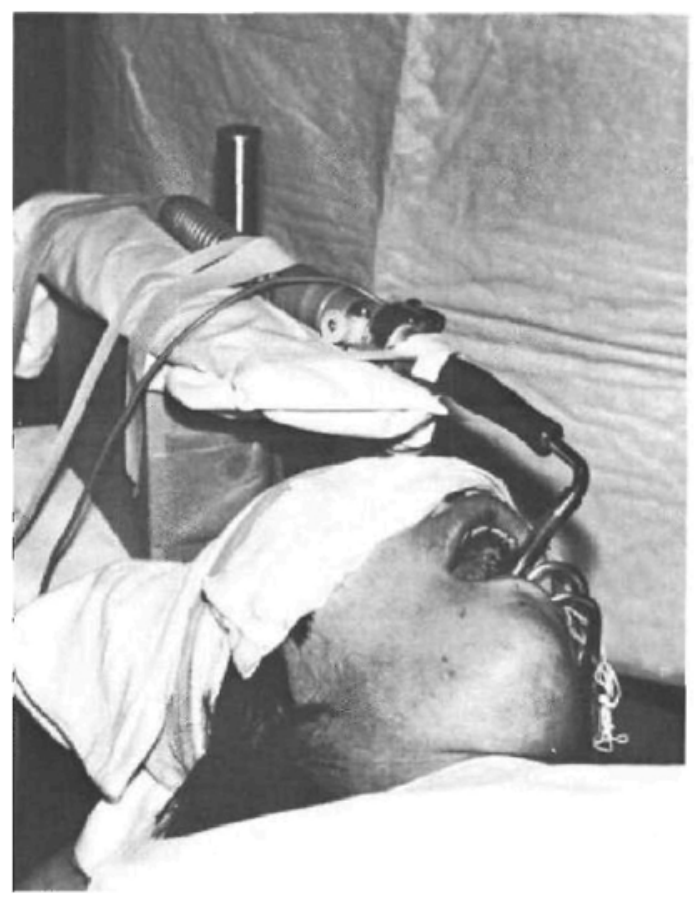

Figure 5

Columbia. Their first child died at two days of age of "cold"; the second girl died before reaching one year from "meningitis and flu."

No information was available whether they had had any skin problems. Then there had been a number of miscarriages. The third boy was born in 1956 and was said to be normal. The fourth boy, born in 1957, was mentally retarded. The ffth boy (our second patient), was born in 1958, and had epidermolysis bullosa. G.S., bom in 1960 , was the youngest in the family. Following him, there were again a number of miscarriages. Both M.S. and G.S. had stayed in hospitals all their lives until adoption by a foster parent in 1969 .

Since epidermolysis bullosa is a rare skin disorder, we were interested to see if there had been any other similar cases admitted to our hospital. On searching in our Medical Records Department, we were able to find one other patient.

Case 3. M.B. was born in 1951. Epidermolysis bullosa was diagnosed soon after birth and she remained in hospital until one year of age. There was no family history of the disease, and her two siblings were normal. She had numerous bullae all over the body, particularly on the hands, knees and feet. Secondary infection with staphylococci and streptococci was also present. Scarring caused moderate contracture of the fingers and limited opening of the mouth. In 1958 and 1963, she had dental work done under general anaesthesia, but unfortunately no detailed anaesthetic records could be traced. There was, however, great difficulty with intubation. In 1966, she was admitted for investigation of 


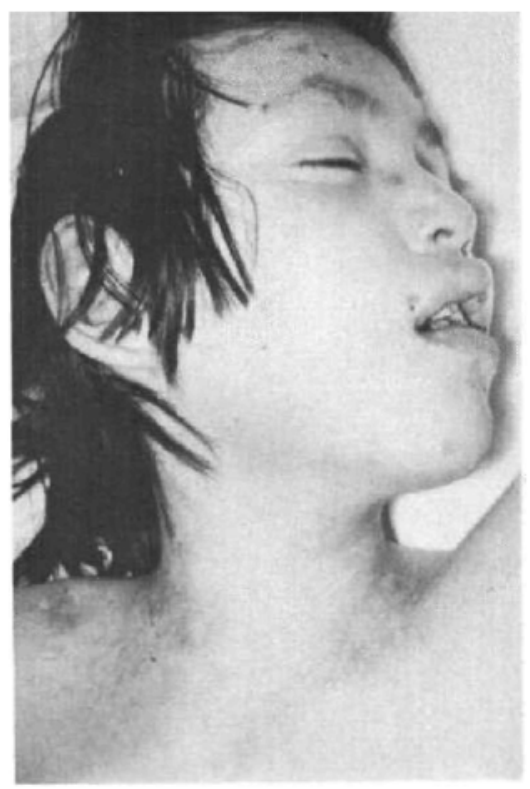

Figure 6

nocturnal grand mal seizure, and was treated with phenobarbital and diphenylhydantoin (Dilantin ${ }^{\$}$ ). Her last admission had been one year ago for treatment of cystitis.

\section{DISCUSSION}

It is obvious that the first two patients had epidermolysis bullosa simplex, and the third patient had epidermolysis bullosa dystrophica of the recessive type. It is generally believed that associated illnesses in patients with this disorder are coincidental. Therefore one probably can put aside the nephritis in the first two patients and the epilepsy in the third. These by themselves cause anaesthetic problems.

There are a number of situations where an anaesthetist may encounter a patient with epidermolysis bullosa (Table I). Apart from these specific procedures, a patient with epidermolysis bullosa is as prone as the general population to other surgical problems entirely unrelated to the disease.

Perhaps the most common situations are oral surgery, dental work ${ }^{7,9}$ and plas. tic reconstruction of hands and fingers, ${ }^{5,6.9}$ the latter usually in patients with the dystrophic type. Our three patients required dental work. No difficulty was encountered in exposing the cords in the first two. However, the third, who had the dystrophic type, did present problems in intubation due to searring around the mouth. It is interesting to note that Young and Hardwick ${ }^{9}$ presented a patient of the dystrophic type with adhesion around the tongue enabling the airway to be easily maintained in two anaesthetics without the use of an artificial airway. 
TABLE I

Potential Situations where Anaesthetists Encounter Patients with Epidermolysis Bullosa

\begin{tabular}{ll}
\hline \hline \multicolumn{1}{c}{ Systen } & \multicolumn{1}{c}{ Procedures } \\
\hline Dental & Extraction, restoration \\
Eyes & Excision of corneal scars, grafting \\
Gastrointestinal & Oesophagoscopy \\
Genitourinary & Cystoscopy \\
Integument & Plastic reconstruction of hands, \\
Obstetrics & excision of carcinoma and grafting \\
\hline
\end{tabular}

Occasionally these patients may come to operation for excision of corneal scars and grafting. Excision of carcinoma and skin grafting have also been done in these patients. ${ }^{13}$ Cystoscopy may be required since these patients are prone to retrograde infections. Most gastroenterologists hesitate to do oesophagoscopy, but occasionally these are done for diagnostic purposes. Lastly, the anaesthetist may encounter a newborn with this disease in the labour room. A potential danger is upper airway obstruction following vigorous suctioning of meconium.

\section{Pre-operative}

\section{Anaesthetic Management}

The anaesthetist must be alert to some of the problems in this disorder when he does his preoperative assessment (Table II).

Most severely affected patients are underdeveloped and their height and body weight should be noted. Therefore, endotracheal tubes cannot be selected according to the age of the patient; one should take this into consideration. One should also look for potential airway problems from scarring.

Many patients have had steroid therapy during the course of their disease, and adequate steroid coverage should be given when indicated. Iron deficiency anaemia is common and severe anaemia should be corrected preoperatively. Serum protein abnormalities from chronic infection and debilitation may have some bearing on the choice of drugs in regard to protein binding. Ideally one would like to check the blood coagulation, since this was found to be abnormal in one study. ${ }^{10}$ No abnormality in serum sodium, potassium, chloride, phosphorus and calcium was observed in these patients. ${ }^{17}$ However, in view of the fact that some patients have developed amyloidosis, it will be wise to check the Blood Urea Nitrogen and to carry out urinalysis.

Marshall ${ }^{25}$ has pointed out that there is a close association between epidermolysis bullosa and porphyria, and that porphyrinuria is found in every case. However, others ${ }^{26}$ have maintained that there is no evidence of a relationship to porphyrin metabolism in this disorder. Certainly porphyrinuria was absent in our first two patients and barbiturates were used in all three patients and no untoward reaction was observed. The same is true in the cases reported by Wilson, ${ }^{8}$ Young and Hardwick, ${ }^{9}$ and Kubota; ${ }^{5}$ porphyrinuria was not present in Marshall's patient. ${ }^{7}$ However, it is still wise to look for porphyria preoperatively. 
TABLE II

\begin{tabular}{l}
$\begin{array}{c}\text { Preoperative Assessment of } \\
\text { Patients with } \\
\text { Eptoermotysis Butlosa }\end{array}$ \\
\hline 1. History of steroid treatment \\
2. Weight and height percentile \\
3. Potential airway problems \\
4. Haemoglobin, white cell counts \\
5. Coagulation studies \\
6. Serum proteins \\
7. Urinalysis \\
8. BUN, serum electrolytes \\
9. Screening for porphyria
\end{tabular}

These patients are self-conscious and apprehensive. A good rapport is essential and adequate sedation should be aimed at in the premedication. Any agent or combination of agents may be used. Barbiturates may be prescribed if porphyria is ruled out. Intramuscular injection is not contra-indicated.

\section{Pre-operative}

The patient should be adequately sedated, as excitement is harmful. If at all possible he should be allowed to move and position himself on the operating table. An intravenous infusion may be started as indicated. No tapes should be used. A soft roll wrapped around the intravenous site is a good way to keep the needle and tubing in place without causing trauma. The intradermal injection of local anaesthetic solution should be avoided, as this can produce a haemorrhagic bullae. Ample padding should be used over pressure points, particularly in long procedures, and repositioning of the patient during the procedure should be kept to the minimum.

Any anaesthetic agent may be used according to the circumstances. For induction, thiopentone ${ }^{8,9}$ cyclopropane, ${ }_{r}^{5}$ droperidol $^{\mathbb{B}}$ and halothane have been used. Thiopentone, if not contraindicated, has the advantage over inhalation agents in the rapid onset of anaesthesia and because it obviates the necessity of fitting a mask over the face. Droperidol is a good altemative. For maintenance of anaesthesia, trichloroethylene, ${ }^{1,8}$ halothane, ${ }^{7,8}$ Fentanyl, ${ }^{6}$ ether, ${ }^{5}$ cyclopropane ${ }^{6}$ and nitrous oxide have been used. Trichloroethylene has the advantage of being a respiratory stimulant, but cannot be used in a closed system with soda lime. Open drop ether is not suitable for oral surgery. Ether and cyclopropane are explosive and should not be used in dental work. An alternative choice would be ketamine, with its advantage of airway patency. Regional anaesthesia has been suggested; ${ }^{*}$ however, because of the fragile skin and secondary skin infection, it is wise to avoid this technique.

When holding the anaesthetic mask in place, the angle of the jaw may be traumatized with consequent bullae formation. ${ }^{3}$ Oxygenation can be achieved by using a high oxygen flow with the mask just over but not actually touching the face. Alternatively, the face can be covered with saline-soaked gauze, and the conjunctiva protected with 5 per cent boric acid in a lanolin base. ${ }^{5}$

If at all possible, an oral tracheal tube is preferred to a nasal tube, and a size 
slightly smaller than usual should be used. It should be well lubricated. Similarly the suction catheter should be well lubricated and pressure kept to the minimum.

The blood pressure cuff may be applied with a thin layer of soft roll padding. Other instrumentations such as oesophageal or precordial stethoscope should be avoided (Case 1).

\section{Post-operative}

Extubation should be gentle. Stridor should be looked for, as it indicates swelling or the forming of bullae in the larynx or trachea. If this happens, one may try to rupture the bullae and apply topical steroids. Tracheostomy itself can cause damage to the trachea.

The patient should be lifted by means of the bed sheet avoiding the slightest shearing movements during transfer from the table to the stretcher.

Emergence from anaesthesia should be smooth and free from excitement. All precautions should be continued in the recovery room and the ward.

\section{RÉsUMé}

Nous présentons une revue de désordres cutanés peu fréquents; l'épidermolyse bulleuse et ses implications avec l'anesthésie; nous rapportons également l'histoire de trois cas cliniques.

Nous proposons un modèle de ligne de conduite à tenir pour l'anesthésie et nous insistons sur la nécessité d'éviter tout traumatisme sur la peau et sur les muqueuses.

\section{ACKNOWLEDGMENTS}

We thank Dr. D.L. McNair for his cooperation during the procedure, Mrs. M. Stephenson for secretarial work and Mr. Ron Valliers for the photography.

\section{REFERENCES}

1. Von Hebra, F. Pemphigus. Arzlicher Bericht des K.K. Allgemeinen Krankenhauses. Vienna: $362-364$ (1870)

2. Fox, $T$. Notes on unusual or rare forms of skin diseases. Lancet 1: 766-767 (1879).

3. Goldschemen, A. Hereditare Neigung zur Blasenbildung, Mschr Prakt Derm. I: 163-164 (1882).

4. Koebner, H. Hereditare Analage Zur Blasenbildung, Deutsch. Med. Wschr. 12: 21-22 (1886)

5. Kobota, Y., Norton, M.L., Goldennerc, S., \& Robentazzi, R.W. Anesthetic management of patients with epidermolysis bullosa undergoing surgery. Anesthesia and Analge$\sin 40: 2,244-250(1961)$.

6. MArx, L.C. et al. Anesthesia in epidermolysis bullosa. Clinical Anesthesia Conference, New York State Journal of Medicine 66: 511-512 (1966).

7. MarsharL, B.E. A comment of epidermolysis bullosa and its anaesthetic management for dental operations. A case report. British Joumal of Anaesthesia 35: 724-727 (1963).

8. WILSON, F. Epidermolysis bullosa: a rare disease of anaesthetic interest. Brit. J. Anaesth. 31: $26-31$ (1959)

9. Young, D.A. \& HafDwick, P.B. Anaesthesia for epidermolysis bullosa dystrophia. A.report of multiple anaesthetics in one patient. Annesthesia 23: 2, 264-267 (1968).

10. Frtzpatricx, T.B. et al. (ed.) Dermatology in general medicine. Boston, MoGraw Hill (1971). 
11. PEArson, R.W. Studies on the pathogenesis of epidermolysis bullosa. J. Invest. Derm. 39: $551-575$ (1962).

12. WaIsMaN, M. Recurrent bullous eruptions of feet and hands (Weber-Cockayne); localized epidermolysis bullosa. J.A.M.A. 124: 1247-1250 (1944).

13. Domonkos, A.N. Andrews' diseases of the skin, dinical dermatology. New York, Saunders $(1971)$.

14. BECKER, M.H. \& SwINYARD, C.A. Epidermolysis bullosa dystrophica in children - radiologic manifestations. Radiology 90: 124-128 (1968).

15. Mazza, C. \& PANAGs, P. A case of scleromalacia perforans with epidermolysis bullosa dystrophica (scleromalacia perforante ed epidermolisi bullosa dystrophica). Ann. Ottal. 93: 373-380 (1967).

16. Tio, T.H., WAARDENBERG, P.J., Vermeulen, H.T. Blood coagulation in epidermolysis bullosa hereditaria. Arch. Derm. (Chicago) 88: 24-3I (1963).

17. Fischer, T. \& LoDis, A. Biochemical studies in epidermolysis bullosa. Acta Dermatovener (Stockholrn) 46: 324-327 (I966).

18. Engman, M.F. Mook, W.H. A study of some cases of epidermolysis bullosa with remarks upon the congenital absence of elastic tissue. J. Cutan. Dis. 24: 55-67 (1986).

19. Encman, M.F. Mook, W.H. A further contribution to the study of elastic tissue in epidermolysis bullosa. J. Cutan. Dis. 28: 275-280 (1910).

20. Eu.tior, G.T. A contribution to the histopathology of epidermolysis bullosa (hereditaria). New York Med. Journal $71: 585-588$ ( 1900 ).

21. Winer, M.M. \& Orman, J.M. Epidermolysis bullosa: a suggestion as to possible causation. Archs. Derm. Syph. 52: 317-321 (1945).

22. Drouet, L. Endocrinides cutanees (sclerodennie, epidermolyse Bulleuse) chez un myxoedemateux. Bull, Soc. Franc, Derm. Syph. 35: 503 (1928).

23. Harcozzi, A. Epidermolisis bullosa distrofica con ematoporfurmutita ed alterazione endocrinosempatica. Arch. Stal. Derm. Vener. 4: 555 (1929).

24. Lundy, J.B., Devalin, C.M., \& Haht-Draut, P. Epidermolysis bullosa. Med. Clin. N. Amer. 169-180 (1932).

25. Marshale, J. Diseases of the skin. Edinburgh, Liningstone (1960).

26. Atl.eN, A.C. The skin! a clinicopathological treatise, 2nd ed., New York, Grune and Stratton (1967).

27. Prlispury, D.M., Shelley, W.B., Klicman, A.M. Dermatology, Pennsylvania, Saunders (1966). 